\title{
Is an Individual Prediction of Maximal Work Rate by 6-Minute Walk Distance and Further Measurements Reliable in Male Patients with Different Lung Diseases?
}

\author{
Uta Ochmann ${ }^{a}$ Nicola Kotschy-Lang ${ }^{b}$ Wolfgang Raabc Jessica Kellberger ${ }^{a}$ \\ Dennis Nowak ${ }^{a}$ Rudolf A. Jörres ${ }^{a}$ \\ anstitute and Outpatient Clinic for Occupational, Social and Environmental Medicine, Inner City Clinic, \\ University Hospital of Munich, Munich, ${ }^{b}$ Rehabilitation Clinic Falkenstein, Berufsgenossenschaftliche Klinik für \\ Berufskrankheiten, Falkenstein, and ${ }^{\mathrm{C}}$ Rehabilitation Clinic Bad Reichenhall, Klinik für Berufskrankheiten der \\ Verwaltungs-Berufsgenossenschaft, Bad Reichenhall, Germany
}

\section{Key Words}

Obstructive lung disease $\cdot$ Restrictive lung disease $\cdot$

Endurance training $\cdot 6$-Minute walk distance $\cdot$ Maximal work rate

\section{Abstract}

Background: In patients with chronic lung diseases, the work rate for endurance training is calculated by the maximal work rate $\left(\mathrm{W}_{\max }\right)$. Because the assessment bears side effects, a prediction by easier accessible tests would be of practical use. Objective: We addressed the reliability of predicting $\mathrm{W}_{\max }$ on the basis of the 6-min walk distance (6MWD) test and a set of further parameters in patients with different lung diseases. Methods: Baseline data of a longitudinal study including $6 \mathrm{MWD}, \mathrm{W}_{\max }$, peripheral muscle force, lung function, fat-free mass and dyspnea (Modified Medical Research Council score) of 255 men with occupational lung diseases (104 asthma, 69 asbestosis, 42 silicosis, 40 chronic obstructive pulmonary disease) were evaluated. Results: $6 \mathrm{MWD}$ correlated with $\mathrm{W}_{\max }(r=0.51, \mathrm{p}<0.05)$. The product of $6 \mathrm{MWD}$ and body weight, in particular fat-free mass, led to an improvement in the correlation of $\mathrm{W}_{\max }$ with 6MWD. Muscle force, lung function and Modified Medical Research
Council score correlated moderately but significantly with $W_{\max }(p<0.05$ each). The maximum correlation gained by including 6MWD and further parameters in the prediction equations was $r=0.76$ in patients with obstructive lung function impairment and $r=0.61$ in asbestosis patients. The residual standard deviations of $\mathrm{W}_{\max }$ predicted by the calculated equations ranged between 20 and $28 \mathrm{~W}$, and the $95 \%$ prediction intervals of $W_{\max }$ ranged between \pm 47 and \pm 65 W. Conclusions: A reliable prediction of individual $\mathrm{W}_{\max }$ by $6 \mathrm{MWD}$ or related measures and therefore a replacement by other tests is not possible. Nevertheless, it may be useful for the comparison of average values in epidemiological and clinical studies.

Copyright $\odot 2013$ S. Karger AG, Basel

\section{Introduction}

Exercise training is a recognized therapy option in patients with chronic respiratory diseases regardless of underlying causes $[1,2]$. Within rehabilitation programs [3], endurance training is usually conducted on cycle ergometers at a work rate of at least $60 \%$ of individual maximal work capacity [3]. The assessment of maximal work ca-

\section{KARGER}

E-Mail karger@karger.com

www.karger.com/res
2013 S. Karger AG, Basel

$0025-7931 / 13 / 0865-0384 \$ 38.00 / 0$
Dr. Uta Ochmann

Institute and Outpatient Clinic for Occupational, Social and Environmental Medicine Inner City Clinic, University Hospital of Munich

Ziemssenstrasse 1, DE-80336 Munich (Germany)

E-Mail uta.ochmann@med.uni-muenchen.de 
pacity requires special equipment and well-trained staff, is expensive, time consuming and bears the risk of side effects.

Therefore, a prediction of the maximal work rate $\left(\mathrm{W}_{\max }\right)$ by more easily assessed measures would be of practical relevance. Regarding patients with chronic obstructive pulmonary disease (COPD), equations for predicting $\mathrm{W}_{\max }$ from the 6-min walk distance (6MWD) test have been presented [4-8]. One study also offered an equation for patients with lung fibrosis [6]. Four of these studies were based on small samples. To evaluate the applicability of prediction, larger study groups with different respiratory diseases are needed.

Based on these considerations, we reanalyzed the baseline data from a large study on the efficacy of rehabilitation [9]. We aimed to quantify the correlations of $\mathrm{W}_{\max }$ with other measures and to assess the maximal reliability of individual prediction by including a broad range of predictors. For clarification, we also compared the results with existing prediction equations for $\mathrm{W}_{\max }$.

\section{Methods}

\section{Study Design and Subjects}

Subjects were recruited within a longitudinal clinical study on the efficacy of pulmonary rehabilitation in 287 patients with occupational lung diseases. Baseline data before intervention were reanalyzed in a subpopulation of 255 men.

This study was approved by the German Social Accident Insurance according to official ethic regulations (project No. FFFB0094). Patients gave their informed consent.

The inclusion criteria were: recognized occupational respiratory disease diagnosed as asthma, asbestosis, silicosis or COPD in coal miners; functional impairment leading to a reduction in earning capacity by $20-50 \%$, age $<75$ years; no rehabilitation in the previous 2 years; maximum exercise capacity of at least $40 \mathrm{~W}$; no progressive malignant diseases; clinically stable.

Assessments included height, age, weight, body fat by nearinfrared light measurement (Futrex 6100 XL, Futrex Inc., USA), spirometry (Master Screen Body, Care Fusion Germany), peripheral muscle force, $6 \mathrm{MWD}, \mathrm{W}_{\max }$ and dyspnea at rest [Modified Medical Research Council (MMRC) questionnaire].

The 6MWD was determined 2 times on the first day (resting time of $\geq 40 \mathrm{~min}$ in between) and once on the following day according to American Thoracic Society guidelines [10]. $\mathrm{W}_{\max }$ was assessed by incremental cycle ergometry test (Master Screen CPX, Care Fusion Germany; e-Bike Basic PC Plus-Ctrl, Ergoline GmbH, Germany). After a resting period of 3 min while already sitting on the ergometer, patients started cycling at a work rate of $30 \mathrm{~W}$. The work rate was increased every 2 min by $20 \mathrm{~W}$ until symptom limitation. $\mathrm{W}_{\max }$ was defined as the highest work rate achieved for at least $30 \mathrm{~s}$.

Quadriceps muscle force was measured by the 'DigiMax-Muskelfunktion-Testcenter' (DigiMax, MechaTronics, Hamm, Ger- many) and handgrip force by a hydraulic hand dynamometer (JAMAR, Lafayette Instrument, USA); the best value of 3 tests was taken. Results were expressed as the sum of both extremities in kilograms.

\section{Statistical Analysis}

For data description, absolute and relative frequencies as well as mean values, standard deviations (SDs) and ranges were computed. Subgroups were compared with each other using one-way analysis of variance (ANOVA) and $\chi^{2}$ tests of contingency tables. If overall differences turned out to be statistically significant, appropriate post hoc multiple comparisons were made using the Student-Newman-Keuls multiple range test. The total group of patients and the subgroups with asthma, asbestosis, silicosis or COPD, or the pooled data of asthma, silicosis and COPD were analyzed. The adequacy and admissibility of ANOVA was checked by standard procedures regarding data distributions and residuals.

Multiple stepwise linear regression analysis of $\mathrm{W}_{\max }$ was used to identify the predictors. To allow practical conclusions, the accuracy of prediction was expressed not only by the explained variance and Pearson correlation coefficients but also by the residual SD of the prediction and the $95 \%$ prediction intervals which refer to the prediction of the value of a newly recruited individual who was not part of the group used for analysis. The level of statistical significance was assumed as $\mathrm{p}=0.05$. All calculations were performed with the software SPSS 19.

\section{Results}

The present study is based on data of the baseline examination of the subgroup of men $(\mathrm{n}=255)$ : 104 with asthma, 42 with silicosis, 69 with asbestosis and 40 with COPD; the subgroup of women was excluded, being too small to allow statistically reliable conclusions. The study was conducted from March 2007 to May 2010. Characteristics of study subjects are given in table 1 .

\section{MWD Test}

The comparison of 6MWD values of the three tests on 2 days is shown in table 2.

Upon statistical testing, the mean difference between the first and second test (mean \pm SD, $16 \pm 34 \mathrm{~m}$ ) turned out to be significantly different from the difference between the second and third test $(6 \pm 42 \mathrm{~m})$. We considered the first test as run-in test and selected the individual best test out of the second and third test.

The results for asthma, silicosis, asbestosis and COPD are shown in table 2.6MWD was shorter in the COPD and silicosis groups compared to the two other groups (ANOVA, $\mathrm{p}<0.05$ each). The mean 6MWD in the total group was $502 \mathrm{~m}$ (range 230-670). 
Table 1. Characteristics of study subjects

\begin{tabular}{|c|c|c|c|c|c|}
\hline & $\begin{array}{l}\text { Asthma } \\
(\mathrm{n}=104)\end{array}$ & $\begin{array}{l}\text { Silicosis } \\
(\mathrm{n}=42)\end{array}$ & $\begin{array}{l}\text { COPD } \\
(n=40)\end{array}$ & $\begin{array}{l}\text { Obstructive group } \\
(\mathrm{n}=186)\end{array}$ & $\begin{array}{l}\text { Asbestosis } \\
(\mathrm{n}=69)\end{array}$ \\
\hline Age, years & $58(8)$ & $64(6)$ & $68(3)$ & $61(8)$ & $63(5)$ \\
\hline Weight, kg & $87.6(15.6)$ & $85.2(13.7)$ & $87.7(15.4)$ & $87.1(15.1)$ & $87.1(13.2)$ \\
\hline FFM, kg & $65.0(7.2)$ & $63.0(4.4)$ & $63.5(6.6)$ & $64.4(10.9)$ & $63.4(6.5)$ \\
\hline BMI & $29.1(4.7)$ & $28.0(3.7)$ & $29.3(5.0)$ & $28.9(4.6)$ & $30.0(3.8)$ \\
\hline FVC, 1 & $3.77(0.99)$ & $3.62(0.59)$ & $3.47(0.72)$ & $3.68(0.87)$ & $3.19(0.73)$ \\
\hline $\mathrm{FEV}_{1}$, \%pred. & $79.4(22.4)$ & $80.9(16.6)$ & $78.0(18.0)$ & $79.4(20.3)$ & $77.8(19.8)$ \\
\hline FVC, \%pred. & $92.3(20.6)$ & $91.7(14.7)$ & $91.7(18.7)$ & $92.3(18.9)$ & $81.8(17.6)$ \\
\hline $\mathrm{FEV}_{1} / \mathrm{VC}, \%$ & $68.0(14.6)$ & $67.5(10.9)$ & $64.3(8.8)$ & $67.1(12.8)$ & $74.2(12.8)$ \\
\hline Handgrip force, $\mathrm{kg}$ & $75.6(18.0)$ & $72.2(18.5)$ & $67.5(14.8)$ & $73.1(17.7)$ & $70.6(18.2)$ \\
\hline Quadriceps force, $\mathrm{kg}$ & $68.3(23.6)$ & $58.3(20.8)$ & $55.2(25.0)$ & $63.2(23.9)$ & $61.6(21.3)$ \\
\hline
\end{tabular}

Data are means, with SDs in parentheses. BMI = Body mass index.

Table 2. Comparison of $6 \mathrm{MWD}$ results of the three tests on 2 days

\begin{tabular}{lrr}
\hline & n & $\%$ \\
\hline Best result in the first test & 13 & 5 \\
Best result in the second test & 62 & 24 \\
Best result in the third test & 124 & 49 \\
Same result in all tests & 13 & 5 \\
Same and best result in the first and second test & 6 & 2 \\
Same and best result in the second and third test & 34 & 13 \\
Same and best result in the first and third test & 3 & 1 \\
\hline
\end{tabular}

\section{Maximal Work Capacity}

ANOVA revealed significantly higher values in asthma patients $(\mathrm{p}<0.05)$. Data are given in table 3 . The mean maximal work capacity in the total population was $112 \mathrm{~W}$ (range 40-230).

\section{Correlation between $6 M W D$ and $W_{\max }$}

The total population showed a significant correlation $(\mathrm{r}=0.51, \mathrm{p}<0.05)$ between $6 \mathrm{MWD}$ and $\mathrm{W}_{\max }$. Figure 1 displays the relationships in the disease groups. When regression lines were tested for differences by pairwise comparisons, intercepts and slopes proved to be similar in the silicosis, asthma and COPD subgroups but different in the asbestosis subgroup $(\mathrm{p}<0.05)$. Based on these results, silicosis, asthma and COPD were analyzed together called 'obstructive group' (table 1). The asbestosis group was analyzed separately. Regression lines and their confidence intervals for both groups are shown in figure 2 .

\section{Correlation of Further Parameters with $W_{\max }$}

Table 4 shows the single correlations between $\mathrm{W}_{\max }$ and additional parameters. To identify the best combinations of predictors, we defined the entities 'walking test', 'lung function' and 'extremity muscle force'.

- Walking test: 6MWD, 6-min walk work (6MWW) calculated by multiplying 6MWD in km and body weight in $\mathrm{kg}$, or 6-min walk fat-free mass (6MWFFM), the product of 6MWD in $\mathrm{km}$ and FFM in $\mathrm{kg}$.

- Lung function: forced expiratory volume in $1 \mathrm{~s}\left(\mathrm{FEV}_{1}\right)$ in liters, forced vital capacity (FVC) in liters, their percent predicted values, or their ratio in percent (Tiffeneau quotient).

- Extremity muscle force: handgrip or quadriceps muscle force.

To deal with the colinearity, multiple linear regression was performed with all possible combinations of just one parameter from each above-mentioned entity to identify the best predictor.

\section{Prediction Models for $W_{\text {max }}$ in Different Groups of Diseases}

In the obstructive group, the maximal overall correlation reached $r=0.758$. In the stepwise multivariate analysis, the anthropometric parameters turned out to become insignificant and were excluded, while 6MWFFM, FVC, MMRC and quadriceps muscle force remained significant ( $p<0.05$ each). Including these measures, the correlation was $\mathrm{r}=0.748$ and the prediction equation is: DOI: $10.1159 / 000345859$
Ochmann/Kotschy-Lang/Raab/

Kellberger/Nowak/Jörres 
Table 3. Results of 6MWD and incremental cycle ergometry test

\begin{tabular}{|c|c|c|c|c|c|}
\hline & $\begin{array}{l}\text { Asthma } \\
(\mathrm{n}=104)\end{array}$ & $\begin{array}{l}\text { Silicosis } \\
(\mathrm{n}=42)\end{array}$ & $\begin{array}{l}\text { COPD } \\
(n=40)\end{array}$ & $\begin{array}{l}\text { Obstructive group } \\
(\mathrm{n}=186)\end{array}$ & $\begin{array}{l}\text { Asbestosis } \\
(\mathrm{n}=69)\end{array}$ \\
\hline Distance, $\mathrm{m}$ & $531(86)$ & $468(70)$ & $444(87)$ & $498(91)$ & $514(96)$ \\
\hline Walk work, $\mathrm{km} \cdot \mathrm{kg}$ & $46.3(10.2)$ & $39.7(7.6)$ & $38.5(8.6)$ & $43.1(10.0)$ & $44.5(9.1)$ \\
\hline Heart rate before exercise, bpm & $80(13)$ & $77(12)$ & $78(12)$ & $79(13)$ & $82(16)$ \\
\hline Heart rate at the end of the test, bpm & $112(17)$ & $115(18)$ & $112(15)$ & $112(17)$ & $113(17)$ \\
\hline $\mathrm{SO}_{2}$ before exercise, $\%$ & $94(2)$ & $94(1)$ & $94(2)$ & $94(2)$ & $94(2)$ \\
\hline $\mathrm{SO}_{2}$ at the end of the test, $\%$ & $94(3)$ & $91(3)$ & $91(4)$ & $93(3)$ & $91(5)$ \\
\hline $\mathrm{W}_{\max }, \mathrm{W}$ & $120(41)$ & $106(31)$ & $106(34)$ & $114(38)$ & $107(26)$ \\
\hline Heart rate before exercise, bpm & $82(13)$ & $78(13)$ & $80(13)$ & $81(13)$ & $83(17)$ \\
\hline Heart rate $\mathrm{W}_{\max }, \mathrm{bpm}$ & $132(21)$ & $126(24)$ & $125(23)$ & $129(22)$ & $127(19)$ \\
\hline
\end{tabular}

Data are means, with SDs in parentheses. $\mathrm{SO}_{2}=$ Peripheral oxygen saturation.

(a) $\mathrm{W}_{\max }$ pred. $=-6.117+2.491 \cdot 6 \mathrm{MWFFM}(\mathrm{km} \cdot \mathrm{kg})-$ $5.926 \cdot \mathrm{MMRC}+10.118 \cdot \mathrm{FVC}(\mathrm{l})+0.232 \cdot$ quadriceps muscle force $(\mathrm{kg})$.

Measurement of quadriceps muscle force is not routinely available. We excluded this predictor despite being statistically significant. The correlation was $r=0.737$ corresponding to the equation:

(b) $\mathrm{W}_{\max }$ pred. $=-1.786+2.793 \cdot 6 \mathrm{MWFFM}(\mathrm{km} \cdot \mathrm{kg})-$ $6.723 \cdot \mathrm{MMRC}+10.748 \cdot \mathrm{FVC}(\mathrm{l})$.

Values of FFM might not be available. The next best model was based on the $6 \mathrm{MWW}$, with a correlation of $\mathrm{r}=0.721$ and the following equation:

(c) $\mathrm{W}_{\max }$ pred. $=9.177+1.621 \cdot 6 \mathrm{MWW}(\mathrm{km} \cdot \mathrm{kg})-$ $8.121 \cdot \mathrm{MMRC}+13.768 \cdot \mathrm{FVC}(\mathrm{l})$.

When substituting $6 \mathrm{MWW}$ by $6 \mathrm{MWD}$, the correlation was reduced to $\mathrm{r}=0.677$ :

(d) $\mathrm{W}_{\max }$ pred. $=2.888+0.140 \cdot 6 \mathrm{MWD}(\mathrm{m})-$ $7.533 \cdot \mathrm{MMRC}+15.224 \cdot \mathrm{FVC}(\mathrm{l})$.

In the asbestosis group, the maximal overall correlation reached $r=0.623$. In the combined, stepwise model, quadriceps muscle force and body mass index were excluded, being insignificant, whereas 6MWD, FVC and MMRC remained significant ( $\mathrm{p}<0.05$ each). The corresponding correlation was $r=0.607$. The equation was as follows:

(e) $\mathrm{W}_{\max }$ pred. $=57.287+0.072 \cdot 6 \mathrm{MWD}(\mathrm{m})-$ 9.456・MMRC + 9.676•FVC (l).

\section{Residuals and Prediction Intervals}

In the obstructive group, SDs of the residuals ranged between 25.678 for equation (a) and 28.108 for equation (d); in the asbestosis group, the SD was 20.859. We also computed $95 \%$ prediction intervals that describe the pre-
Table 4. Single correlations of $\mathrm{W}_{\max }$ and further variables

\begin{tabular}{|c|c|c|c|c|}
\hline \multirow[t]{2}{*}{ Variable } & \multicolumn{2}{|c|}{$\begin{array}{l}\text { Obstructive } \\
\text { group }(\mathrm{n}=186)\end{array}$} & \multicolumn{2}{|c|}{$\begin{array}{l}\text { Asbestosis group } \\
(n=69)\end{array}$} \\
\hline & $\mathrm{r}$ & $\mathrm{p}$ & $\mathrm{r}$ & $\mathrm{p}$ \\
\hline 6MWD, m & 0.550 & $<0.01$ & 0.452 & $<0.01$ \\
\hline $6 \mathrm{MWW}, \mathrm{km} \cdot \mathrm{kg}$ & 0.606 & $<0.01$ & 0.322 & $<0.01$ \\
\hline $6 \mathrm{MWFFM}, \mathrm{km} \cdot \mathrm{kg}$ & 0.679 & $<0.01$ & 0.049 & 0.688 \\
\hline Body weight, kg & 0.213 & $<0.01$ & 0.153 & 0.210 \\
\hline Body height, m & 0.321 & $<0.01$ & 0.134 & 0.272 \\
\hline Age, years & 0.338 & $<0.01$ & 0.210 & 0.083 \\
\hline BMI & 0.105 & 0.135 & 0.281 & 0.020 \\
\hline FFM, kg & 0.351 & $<0.01$ & 0.015 & 0.905 \\
\hline MMRC, nominal scale & 0.432 & $<0.01$ & 0.456 & $<0.01$ \\
\hline Handgrip force, $\mathrm{kg}$ & 0.474 & $<0.01$ & 0.224 & 0.064 \\
\hline Quadriceps force, $\mathrm{kg}$ & 0.429 & $<0.01$ & 0.268 & 0.026 \\
\hline $\mathrm{FEV}_{1,1}$ & 0.506 & $<0.01$ & 0.301 & 0.012 \\
\hline $\mathrm{FEV}_{1}, \%$ pred. & 0.369 & $<0.01$ & 0.225 & 0.063 \\
\hline FVC, 1 & 0.542 & $<0.01$ & 0.335 & $<0.01$ \\
\hline FVC, \%pred. & 0.381 & $<0.01$ & 0.257 & 0.033 \\
\hline $\mathrm{FEV}_{1} / \mathrm{FVC}, \%$ & 0.130 & 0.076 & 0.135 & 0.267 \\
\hline
\end{tabular}

$\mathrm{r}=$ Correlation coefficient (Pearson); BMI = body mass index.

diction for a newly included patient. Prediction intervals were calculated with $6 \mathrm{MWD}$ being the only independent variable in linear regression to ensure the comparability between regressions and the literature. Details concerning the single disease groups are given in table 5. The 95\% prediction intervals are also graphically demonstrated in figure 1, in addition to the individual values and the regression line. 
Fig. 1. a-d Relationship between 6MWD and $\mathrm{W}_{\text {max }}$. Regression lines (solid lines) and their equations are given for the four disease groups, as well as $95 \%$ prediction intervals (dashed lines) for a newly included individual.

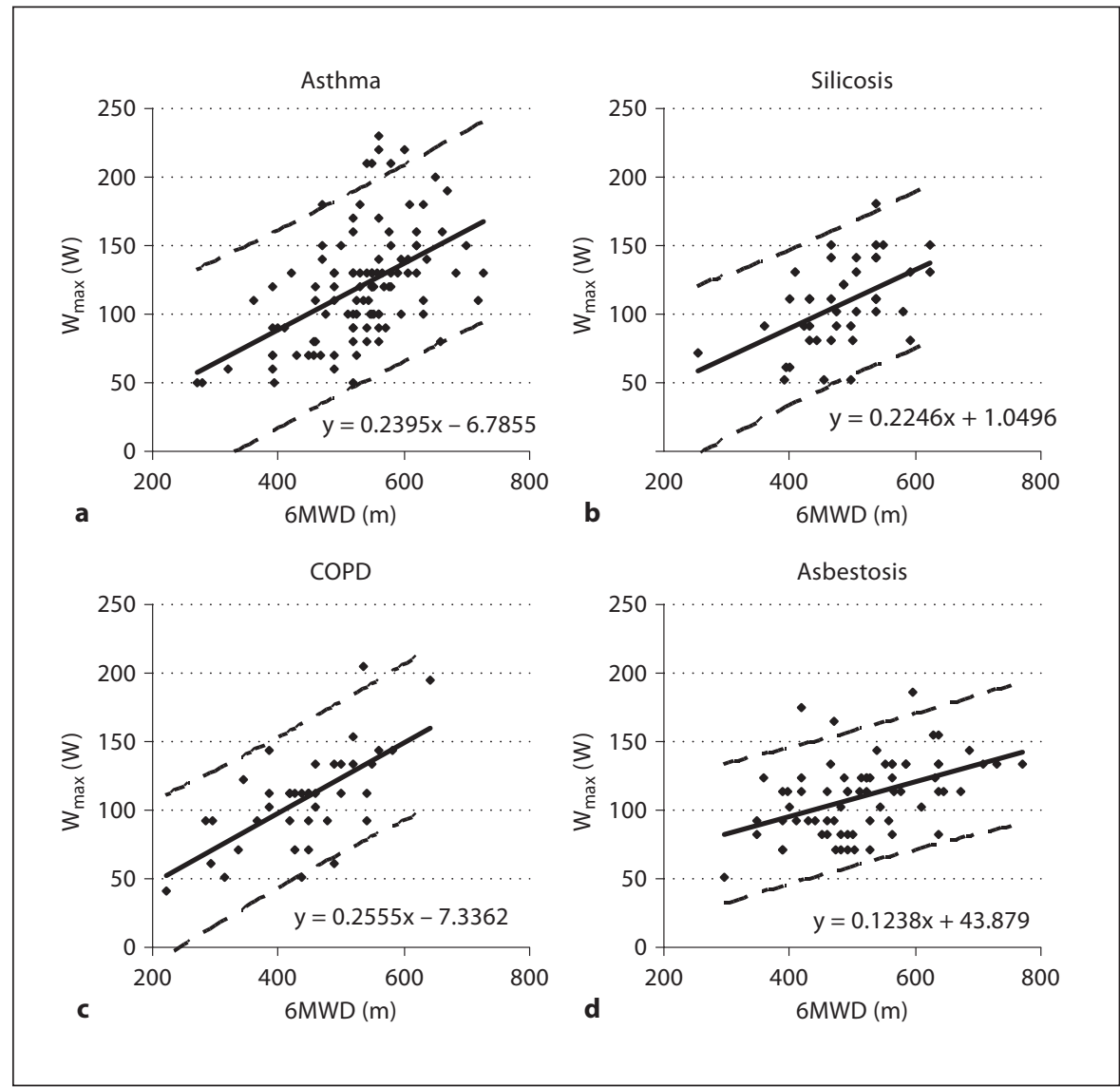

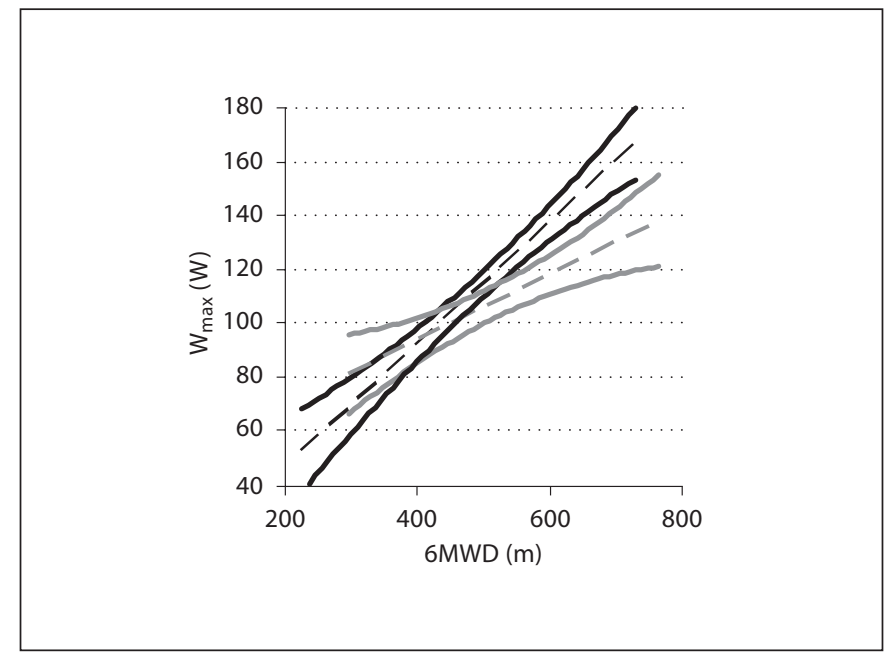

Fig. 2. Confidence intervals of the regression lines of $W_{\max }$ as function of 6MWD. Regression lines (dashed lines) and their 95\% confidence intervals (solid lines) for $\mathrm{W}_{\max }$ as function of $6 \mathrm{MWD}$ in the obstructive group (black) and the asbestosis group (grey).

\section{Comparison with Prediction Equations from the Literature}

Figure 3 a illustrates the residuals of predicted $\mathrm{W}_{\max }$ of the obstructive group in dependence of the $6 \mathrm{MWD}$, using equation (a) as given above. For comparison, we applied the four equations for estimating $\mathrm{W}_{\max }$ as found in the literature [4-7] to the data of our population. The residuals of these calculations are shown in figure $3 \mathrm{~b}-\mathrm{e}$. The same was done for the asbestosis group using equation (e) and the one equation from the literature [6] for estimating $\mathrm{W}_{\max }$ in lung fibrosis patients, as demonstrated in figure $4 \mathrm{~b}$.

\section{Discussion}

Training of exercise capacity is an important issue in the rehabilitation of patients with chronic lung diseases [11]. Commonly, the intensity of training is calculated by the maximal work capacity. The prediction of maximal work capacity by more easily assessed measures would be of practical value. 
Table 5. 95\% prediction intervals of $\mathrm{W}_{\max }$ for a newly studied patient at different levels of the 6MWD

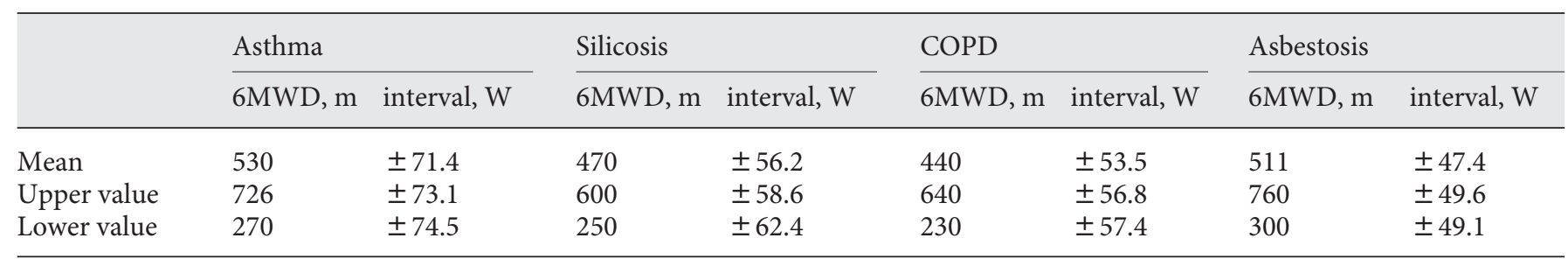

We found significant correlations between $\mathrm{W}_{\max }$ and $6 \mathrm{MWD}$ or related measures in a large population of patients with four different respiratory disorders in men $(\mathrm{n}=255)$. The correlations were weaker than those reported in the literature [4-8]. This might be explained by our less homogeneous but, from a clinical perspective, more realistic patient cohort. We aimed to evaluate a broad panel of predictors of $\mathrm{W}_{\max }$ from a statistical point of view, but also to analyze subsets of predictors that are likely to be available in clinical practice.

In patients with obstructive airway diseases comprising asthma, COPD and silicosis, the correlations with $\mathrm{W}_{\max }$ were homogeneous and could be pooled. The product of $6 \mathrm{MWD}$ and FFM proved to be a better predictor than 6MWD itself or than walk work, i.e. the product of $6 \mathrm{MWD}$ and body weight. These findings are in accordance with published data [12]. Since COPD patients often exhibit reduced muscle mass relative to body weight, the FFM reflects the actual muscle mass better than body weight [4].

The prediction of $\mathrm{W}_{\max }$ was improved by including dyspnea score, FVC and quadriceps muscle force. The MMRC is a simple means for assessing the impact of breathlessness in daily life. It has been described to be correlated with FVC as well as with 6MWD [13].

Concerning lung function, FVC was the best predictor, independent of the lung disease. In restrictive disorders, vital capacity is directly affected, and thus, a correlation is plausible [14]. In COPD, the correlation can be explained by a reduced inspiratory capacity due to dynamic lung hyperinflation $[15,16]$. In advanced COPD, dynamic hyperinflation is observed not only in maximal exercise testing but also after the 6MWD $[17,18]$.

In patients with obstructive lung disorders, quadriceps muscle force was an additional predictor of $\mathrm{W}_{\max }$. Besides lung function impairment and dyspnea, peripheral muscle weakness contributes to exercise limitation in COPD [19]. Quadriceps muscle weakness could be shown to occur in about $25 \%$ of patients with COPD without correlation to disease severity [20]. Quadriceps muscle dysfunction can be found not only if FFM is reduced but also in some patients with preserved FFM [21].

Patients with asbestosis, resembling a restrictive lung disorder, showed a weaker relationship between $\mathrm{W}_{\max }$ and $6 \mathrm{MWD}$ compared to obstructive diseases. Inclusion of the FVC and MMRC improved the correlation.

Although we have included many predictors, even the optimal regression model explained only $57 \%$ of variance in the obstructive group, and in the asbestosis group $<50 \%$. Other unknown factors must have contributed to this result or the inherent variability of tests plays a role. Both 6MWD and $\mathrm{W}_{\max }$ address exercise tolerance, both depending on motivation. While 6MWD is sensitive in patients with advanced impairment, its value is limited in less impaired patients due to a ceiling effect. This might explain part of the variability in the relationship between both measures. Problems of coordination may also have a different impact.

The $6 \mathrm{MWD}$ is known to exhibit a learning effect [22, $23]$. In our data, the first $6 \mathrm{MWD}$ was significantly shorter, whereas the second and third test did not differ statistically. This confirms that one training test is necessary to gain reliable results. Eiser et al. [22] calculated an $8 \%$ intrasubject variation of $6 \mathrm{MWD}$. In our population, this would correspond to a variation between about 18 and $58 \mathrm{~m}$ for the minimum and maximum 6MWD. This also limits the accuracy of prediction. A variation of $50 \mathrm{~m}$ in $6 \mathrm{MWD}$ would induce a variation of predicted $\mathrm{W}_{\max }$ of $11.6 \mathrm{~W}$.

The reproducibility of $\mathrm{W}_{\max }$ is more difficult to assess as the test aims at exhaustion. Literature data suggest an intrasubject variability of about $10 \%$ in COPD [24-26]. In our study, a variability of $10 \%$ would correspond to variations between 4 and $23 \mathrm{~W}$, and about $11.4 \mathrm{~W}$ on average. The variability of predicted $\mathrm{W}_{\max }$ as indicated by the residual SD was much larger. This confirms the assumption that the variability in the predictor $6 \mathrm{MWD}$ also has an impact on the reliability of the predicted $\mathrm{W}_{\max }$. As a re- 


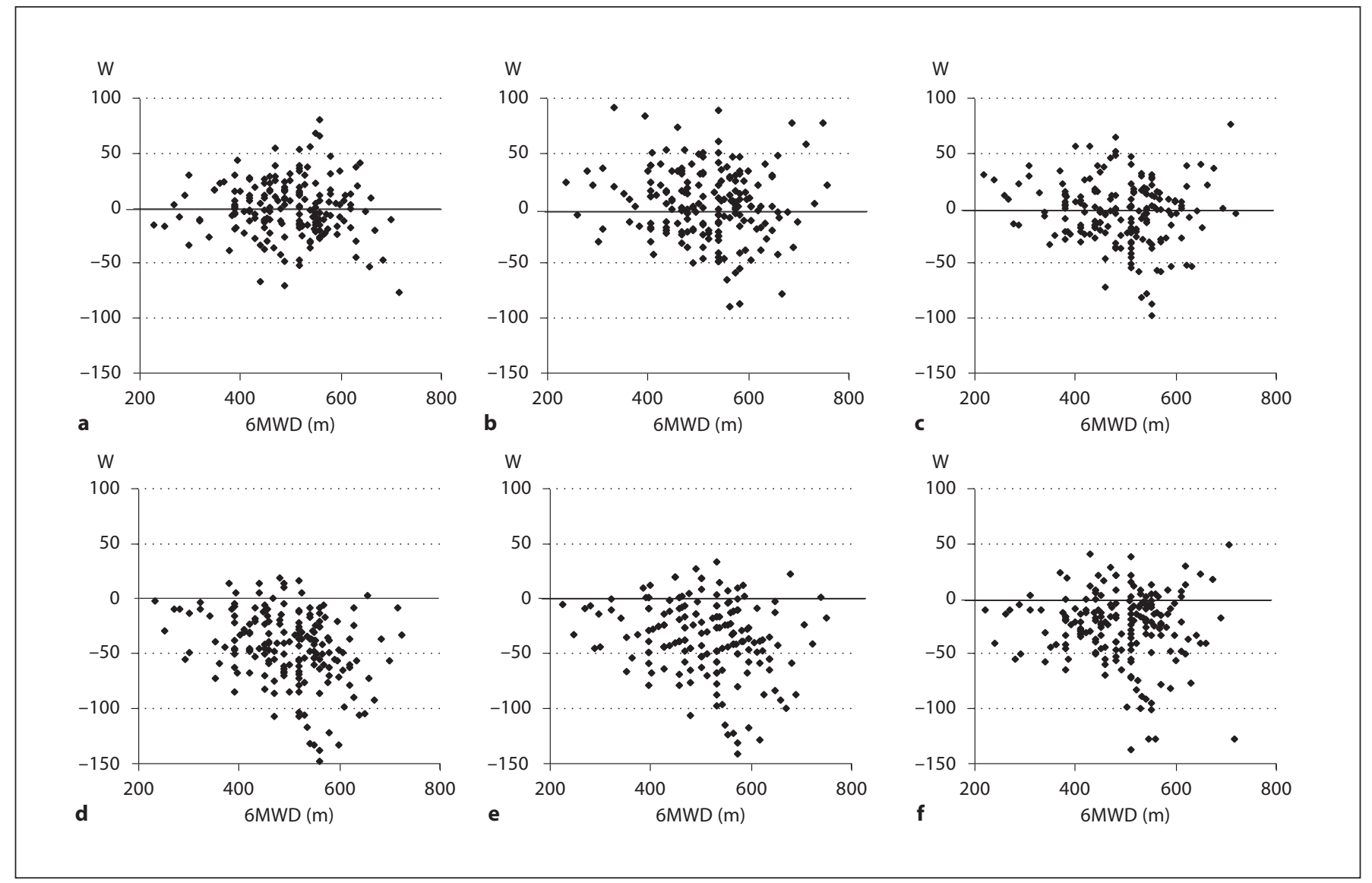

Fig. 3. a-f Residuals of predicted $\mathrm{W}_{\max }$ of COPD patients in comparison to residuals of other equations in the literature applied to the data set. a Residuals of data from this study according to equation (a) (see Results) in the obstructive group $(n=186)$ versus the 6MWD. b-f Residuals, having applied equations from references [4-8] to the data from this study for the obstructive group $(\mathrm{n}=$
186) versus the 6MWD. b $103.217+30.500$ (= male gender) + $[-1.613 \cdot$ age $($ years $)+(0.002 \cdot 6 \mathrm{MWW}[\mathrm{km} \cdot \mathrm{kg}])][7]$. c $-51.994-$ $0.505(=$ male gender $)-[0.234 \cdot$ age (years) $]+[0.091 \cdot$ height $(\mathrm{cm})]$ $+[0.132 \cdot 6 \mathrm{MWD}(\mathrm{m})][8] . \mathbf{d} 17.393+[1.442 \cdot 6 \mathrm{MWW}(\mathrm{km} \cdot \mathrm{kg})][5]$. e $2.310 \cdot 6 \mathrm{MWW}(\mathrm{km} \cdot \mathrm{kg})+8.820[6] . \mathbf{f}-27.9717+[3.7792 \cdot 6 \mathrm{MWFFM}$ $(\mathrm{km} \cdot \mathrm{kg})][4]$.
Fig. 4. a, b Residuals of predicted $\mathrm{W}_{\max }$ of asbestosis patients in comparison to residuals of the equation in the literature for idiopathic pulmonary fibrosis patients applied to the data set. a Residuals of the present data according to equation (e) (see Results) in the asbestosis group ( $n=69)$ versus the $6 \mathrm{MWD}$. b Residuals according to the equation from reference [6] $(0.122 \cdot 6 \mathrm{MWD})+(0.387 \cdot \mathrm{FVC} \%$ pred. $)-$ 21.474 applied to our own data, for the asbestosis group $(n=69)$, versus the 6MWD.

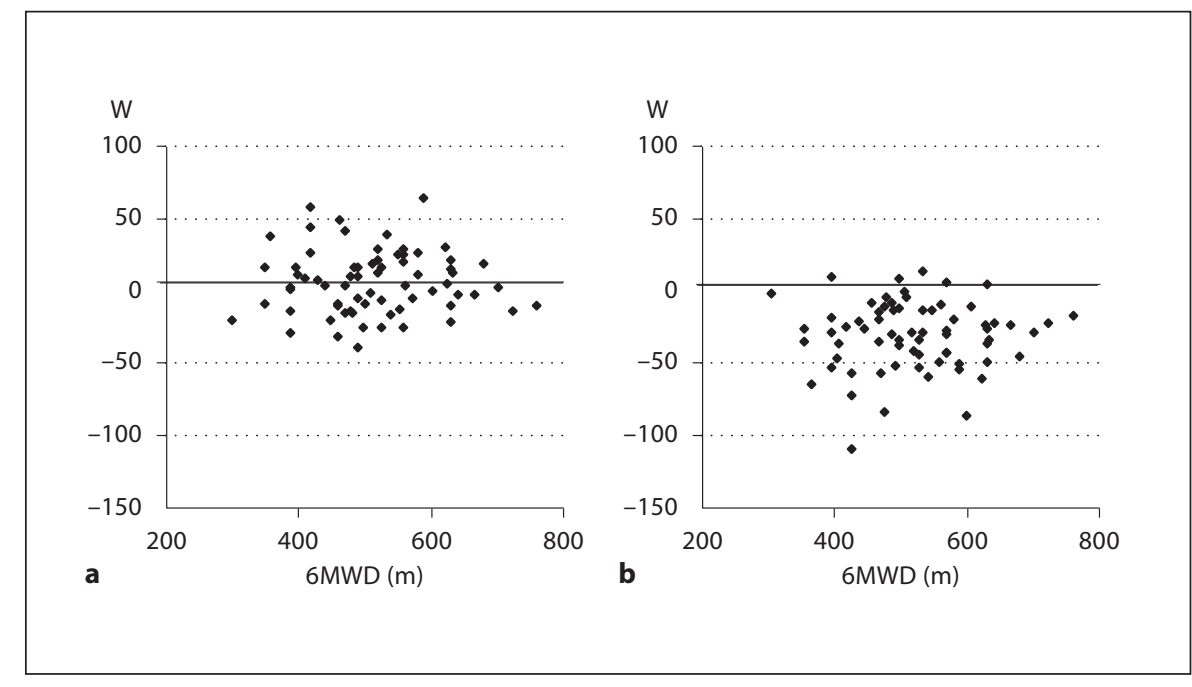


sult, even in the optimal models, the $95 \%$ prediction intervals were wide and the maximally achievable accuracy of prediction in single individuals is low. Sillen et al. [8] came to a similar conclusion: even after calculating a regression equation in a COPD cohort of nearly 3,000 patients using $6 \mathrm{MWD}$, anthropometric parameters and $\mathrm{FEV}_{1}$ as predictors, the estimation of $\mathrm{W}_{\max }$ was too inaccurate to be of practical value in an individual. Ross et al. [27] stated a comparable result for the estimation of peak oxygen uptake via 6MWD, with data indicating a residual standard error of peak $\mathrm{VO}_{2}$ as high as $26.7 \%$.

For clarification and comparison, we also applied published prediction equations of $\mathrm{W}_{\max }$ to our data. Optional additional predictors in these studies were age, gender, body weight or FFM and $\mathrm{FEV}_{1}$. In the obstructive group, the residuals of two equations $[7,8]$ showed similar variance and distribution to our equation, with gender being part of both equations. However, the other three equations [4-6] led to a systemic deviation towards an underestimation of $\mathrm{W}_{\max }$, getting worse with increasing $6 \mathrm{MWD}$. In these three studies, gender was not part of the equation despite having evaluated a mixed group. Holland et al. [28] also found considerable differences between three equations from literature estimating $\mathrm{W}_{\max }$ from $6 \mathrm{MWD}$ after applying them to 64 COPD patients; in men, the variation reached $47 \%$. Besides the abovementioned limited reproducibility of the applied methods, diverse protocols for cycle ergometer testing and inclusion of different predictors may also contribute to the identified differences. Only one equation from the literature [8] included a lung function parameter. Pretto et al. [29] did not use the 6MWD but baseline respiratory function as the only predictor of $\mathrm{W}_{\max }$; the correlation was 0.85 . This underlines the importance to include measures of lung function impairment when predicting $\mathrm{W}_{\max }$. The equation for lung fibrosis [6] has been assessed in an Asian population and included FVC as an additional predictor. The application to our data led to residuals which showed a systematic deviation toward lower values independent of the $6 \mathrm{MWD}$ value, probably caused by different anthropometry.

\section{Limitations of the Study}

We included asthma patients who exhibited $\mathrm{W}_{\max }$ $>200 \mathrm{~W}$. In these patients, the 6MWD might not be an appropriate test. Due to the ceiling effect of the walking distance, the slope of the prediction equation could be calculated higher than in a more physically impaired cohort.
When comparing different prediction equations, the underlying study protocols and inclusion criteria may differ and comparability may be hampered. In addition, the specific populations have to be taken into account. Three equations were assessed in Australia and the Netherlands, countries with populations that can be regarded similar to German anthropometry. In the case of the other two equations, based on a Brazilian and an Asian population, the value of a comparison to a European population is limited because the anthropometric characteristics of the patients may differ considerably. This could lead to a different degree of correlation between the analyzed parameters, as well as to divergent slope and intercept of the regression line of the prediction equation.

\section{Conclusion}

Our results confirm the possibility to predict $\mathrm{W}_{\max }$ from 6MWD and related measures, but the achievable accuracy of prediction in single individuals is too low to be of practical value. A replacement of the individual assessment of $\mathrm{W}_{\max }$ by other tests cannot be advised.

Despite this, the prediction equations which we established on the basis of a large, heterogeneous data set might be useful for the estimation of average values in epidemiological and clinical studies, when cohorts in which $\mathrm{W}_{\max }$ has either been or not been determined are to be compared.

\section{Acknowledgements}

This study was supported and approved by the DGUV, German Social Accident Insurance (registered umbrella association of the accident insurance institutions for the industrial and public sectors).

References $\quad 1$ Grunig E, Ehlken N, Ghofrani A, Staehler G, Meyer FJ, Juenger J, Opitz CF, Klose $\mathrm{H}$, Wilkens H, Rosenkranz S, Olschewski H, Halank M: Effect of exercise and respiratory training on clinical progression and survival in patients with severe chronic pulmonary hypertension. Respiration 2011;81:394-401.

-2 Ferrazza AM, Martolini D, Valli G, Palange $\mathrm{P}$ : Cardiopulmonary exercise testing in the functional and prognostic evaluation of patients with pulmonary diseases. Respiration 2009;77:3-17. 
-3 Nici L, Donner C, Wouters E, Zuwallack R, Ambrosino N, Bourbeau J, Carone M, Celli B, Engelen M, Fahy B, Garvey C, Goldstein R, Gosselink R, Lareau S, MacIntyre N, Maltais F, Morgan M, O'Donnell D, Prefault C, Reardon J, Rochester C, Schols A, Singh S, Troosters T: American Thoracic Society/European Respiratory Society statement on pulmonary rehabilitation. Am J Respir Crit Care Med 2006;173:1390-1413.

-4 Cavalheri V, Hernandes NA, Camillo CA, Probst VS, Ramos D, Pitta F: Estimation of maximal work rate based on the 6-minute walk test and fat-free mass in chronic obstructive pulmonary disease. Arch Phys Med Rehabil 2010;91:1626-1628.

- 5 Hill K, Jenkins SC, Cecins N, Philippe DL, Hillman DR, Eastwood PR: Estimating maximum work rate during incremental cycle ergometry testing from six-minute walk distance in patients with chronic obstructive pulmonary disease. Arch Phys Med Rehabil 2008;89:1782-1787.

-6 Kozu R, Jenkins S, Senjyu H, Mukae H, Sakamoto N, Kohno S: Peak power estimated from 6-minute walk distance in Asian patients with idiopathic pulmonary fibrosis and chronic obstructive pulmonary disease. Respirology 2010;15:706-713.

7 Luxton N, Alison JA, Wu J, Mackey MG: Relationship between field walking tests and incremental cycle ergometry in COPD. Respirology 2008; 13:856-862.

-8 Sillen MJ, Vercoulen JH, Hul AJ, Klijn PH, Wouters EF, van Ranst D, Peters JB, van Keimpema AR, Franssen FM, Otten HJ, Molema J, Jansen JJ, Spruit MA: Inaccuracy of estimating peak work rate from six-minute walk distance in patients with COPD. COPD 2012;9:281-288.

-9 Ochmann U, Kotschy-Lang N, Raab W, Kellberger J, Nowak D, Jörres RA: Long-term efficacy of pulmonary rehabilitation in patients with occupational respiratory diseases. Respiration 2012;84:396-405.

10 ATS/ACCP: ATS/ACCP statement on cardiopulmonary exercise testing. Am J Respir Crit Care Med 2003;167:211-277.
11 Clini EM, Crisafulli E: Exercise capacity as a pulmonary rehabilitation outcome. Respiration 2009; 77:121-128.

12 Carter R, Holiday DB, Nwasuruba C, Stocks J, Grothues C, Tiep B: 6-minute walk work for assessment of functional capacity in patients with copd. Chest 2003;123:1408-1415.

-13 Bestall JC, Paul EA, Garrod R, Garnham R, Jones PW, Wedzicha JA: Usefulness of the Medical Research Council (MRC) dyspnoea scale as a measure of disability in patients with chronic obstructive pulmonary disease. Thorax 1999;54:581-586.

14 Nishiyama O, Taniguchi H, Kondoh Y, Kimura T, Ogawa T, Watanabe F, Arizono S: Quadriceps weakness is related to exercise capacity in idiopathic pulmonary fibrosis. Chest 2005;127:2028-2033.

15 Cooper CB: The connection between chronic obstructive pulmonary disease symptoms and hyperinflation and its impact on exercise and function. Am J Med 2006;119:21-31.

16 O’Donnell DE: Hyperinflation, dyspnea, and exercise intolerance in chronic obstructive pulmonary disease. Proc Am Thorac Soc 2006;3:180-184.

-17 Callens E, Graba S, Gillet-Juvin K, Essalhi M, Bidaud-Chevalier B, Peiffer C, Mahut B, Delclaux $C$ : Measurement of dynamic hyperinflation after a 6-minute walk test in patients with COPD. Chest 2009;136:1466-1472.

18 Marin JM, Carrizo SJ, Gascon M, Sanchez A, Gallego B, Celli BR: Inspiratory capacity, dynamic hyperinflation, breathlessness, and exercise performance during the 6-minutewalk test in chronic obstructive pulmonary disease. Am J Respir Crit Care Med 2001;163: 1395-1399.

19 Gosselink R, Troosters T, Decramer M: Peripheral muscle weakness contributes to exercise limitation in COPD. Am J Respir Crit Care Med 1996;153:976-980.
20 Seymour JM, Spruit MA, Hopkinson NS, Natanek SA, Man WD, Jackson A, Gosker HR, Schols AM, Moxham J, Polkey MI, Wouters EF: The prevalence of quadriceps weakness in COPD and the relationship with disease severity. Eur Respir J 2010;36:81-88.

-21 Franssen FM, Broekhuizen R, Janssen PP, Wouters EF, Schols AM: Limb muscle dysfunction in COPD: effects of muscle wasting and exercise training. Med Sci Sports Exerc 2005;37:2-9

22 Eiser N, Willsher D, Dore CJ: Reliability, repeatability and sensitivity to change of externally and self-paced walking tests in COPD patients. Respir Med 2003;97:407-414.

23 Chatterjee AB, Rissmiller RW, Meade K, Paladenech C, Conforti J, Adair NE, Haponik EF, Chin R Jr: Reproducibility of the 6-minute walk test for ambulatory oxygen prescription. Respiration 2010;79:121-127.

-24 Noseda A, Carpiaux JP, Prigogine T, Schmerber J: Lung function, maximum and submaximum exercise testing in COPD patients: reproducibility over a long interval. Lung 1989;167:247-257.

25 Covey MK, Larson JL, Alex CG, Wirtz S, Langbein WE: Test-retest reliability of symptom-limited cycle ergometer tests in patients with chronic obstructive pulmonary disease. Nurs Res 1999;48:9-19.

26 Marciniuk DD, Watts RE, Gallagher CG: Reproducibility of incremental maximal cycle ergometer testing in patients with restrictive lung disease. Thorax 1993;48:894-898.

27 Ross RM, Murthy JN, Wollak ID, Jackson AS: The six minute walk test accurately estimates mean peak oxygen uptake. BMC Pulm Med 2010;10:31.

28 Holland AE, Hill K, Alison JA, Luxton N, Mackey MG, Hill CJ, Jenkins SC: Estimating peak work rate during incremental cycle ergometry from the 6-minute walk distance: differences between reference equations. Respiration 2011;81:124-128.

-29 Pretto JJ, Braun GW, Guy PA: Using baseline respiratory function data to optimize cycle exercise test duration. Respirology 2001;6: 287-291. 